\title{
Hippocampal Dysfunction Provoked by Mercury Chloride Exposure: Evaluation of Cognitive Impairment, Oxidative Stress, Tissue Injury and Nature of Cell Death
}

\author{
Walessa Alana Bragança Aragão, ${ }^{1}$ Francisco Bruno Teixeira, ${ }^{1}$ \\ Nathalia Carolina Fernandes Fagundes, ${ }^{1}$ Rafael Monteiro Fernandes, ${ }^{1}$ \\ Luanna Melo Pereira Fernandes, ${ }^{2}$ Márcia Cristina Freitas da Silva, ${ }^{1}$ Lilian Lund Amado, ${ }^{3}$ \\ Fernanda Espírito Santo Sagica, ${ }^{4}$ Edivaldo Herculano Correa Oliveira, ${ }^{4}$ \\ Maria Elena Crespo-Lopez $\left(\mathbb{D},{ }^{5}\right.$ Cristiane Socorro Ferraz Maia $\left(\mathbb{D},{ }^{2}\right.$ \\ and Rafael Rodrigues Lima ${ }^{1}{ }^{1}$ \\ ${ }^{1}$ Laboratory of Functional and Structural Biology, Institute of Biological Sciences, Federal University of Pará, Belém, PA, Brazil \\ ${ }^{2}$ Laboratory of Pharmacology of Inflammation and Behavior, Institute of Health Sciences, Federal University of Pará, Belém, \\ PA, Brazil \\ ${ }^{3}$ Laboratory of Ecotoxicology, Institute of Biological Sciences, Federal University of Pará, Belém, PA, Brazil \\ ${ }^{4}$ Laboratory of Tissue Culture and Cytogenetics, Evandro Chagas Institute, Ananindeua, PA, Brazil \\ ${ }^{5}$ Laboratory of Molecular Pharmacology, Institute of Biological Sciences, Federal University of Pará, Belém, PA, Brazil
}

Correspondence should be addressed to Rafael Rodrigues Lima; rafalima@ufpa.br

Received 22 November 2017; Revised 31 January 2018; Accepted 21 February 2018; Published 10 April 2018

Academic Editor: Julia Bornhorst

Copyright (C) 2018 Walessa Alana Bragança Aragão et al. This is an open access article distributed under the Creative Commons Attribution License, which permits unrestricted use, distribution, and reproduction in any medium, provided the original work is properly cited.

\begin{abstract}
Mercury (Hg) is a highly toxic metal, which can be found in its inorganic form in the environment. This form presents lower liposolubility and lower absorption in the body. In order to elucidate the possible toxicity of inorganic Hg in the hippocampus, we investigated the potential of low doses of mercury chloride $\left(\mathrm{HgCl}_{2}\right)$ to promote hippocampal dysfunction by employing a chronic exposure model. For this, 56 rats were exposed to $\mathrm{HgCl}_{2}(0.375 \mathrm{mg} / \mathrm{kg} /$ day $)$ via the oral route for 45 days. After the exposure period, the animals were submitted to the cognitive test of fear memory. The hippocampus was collected for the measurement of total $\mathrm{Hg}$ levels, analysis of oxidative stress, and evaluation of cytotoxicity, apoptosis, and tissue injury. It was observed that chronic exposure to inorganic $\mathrm{Hg}$ promotes an increase in mercury levels in this region and damage to short- and long-term memory. Furthermore, we found that this exposure model provoked oxidative stress, which led to cytotoxicity and cell death by apoptosis, affecting astrocytes and neurons in the hippocampus. Our study demonstrated that inorganic $\mathrm{Hg}$, even with its low liposolubility, is able to produce deleterious effects in the central nervous system, resulting in cognitive impairment and hippocampal damage when administered for a long time at low doses in rats.
\end{abstract}

\section{Introduction}

Mercury (Hg) represents the third most toxic element on the planet, according to the US Government Agency for Toxic Substances and Disease Registry [1]. Three forms of $\mathrm{Hg}$ can occur in the environment: organic $\mathrm{Hg}$, elemental $\mathrm{Hg}$, and inorganic $\mathrm{Hg}[2]$.

Organic $\mathrm{Hg}$ is one of the most toxic substances, with the highest number of studies dealing with their effects on human health [2-5]. It is known that organic $\mathrm{Hg}$ has a high 
capacity to cross cellular membranes. After ingestion, it can pass through the blood-brain barrier and be metabolized to inorganic $\mathrm{Hg}$, which is therefore present at low doses in the central nervous system (CNS) $[1,2,6]$.

Human populations throughout the world are chronically exposed to different species of $\mathrm{Hg}$ compounds [7-10]. Amazonian populations, for example, are exposed to $\mathrm{Hg}$ vapor due to the use of this metal in artisanal processes and small-scale gold mining $[7,8]$. Additionally, because of the contaminated environment, populations living downstream of the mining areas or near dams (large-scale projects that may concentrate $\mathrm{Hg}$ in the environment) are exposed to both organic and inorganic mercury $[8,10]$. The latter exposure is predominantly via the oral route due to contaminated food (mainly piscivorous fish) [11]. Once inside the human body, cells of CNS origin are able to accumulate organic mercury and partially transform it to inorganic mercury [6].

Although the additional effects of $\mathrm{Hg}$ intoxication (such as cardiovascular alterations and genotoxicity) are still being described, neurological symptoms are the main deleterious consequences of intoxication by this metal. These include alterations of motor coordination, progressive deterioration of visual and tactile senses, and paralysis, among others. Recent studies in both animals and humans also point to altered cognitive function, especially in memory and learning performance, caused by $\mathrm{Hg}$ exposure $[12,13]$.

The hippocampus is responsible for consolidating two types of memory, storage and recall of events. One of the memory types is aversive memory, related to emotions and reactions of fear and alertness, presenting the hippocampus and amygdala as regulatory areas [14]. The biochemical events occur at neural transmission routes, in which the hippocampus represents an area of huge importance in cognitive and behavioral analysis [14].

In the hippocampus, previous studies verified the presence of increased levels of $\mathrm{Hg}$ in the neural parenchyma after chronic exposure to $\mathrm{HgCl}_{2}$ [15], showing that $\mathrm{Hg}$ presents less tropism for the hippocampus when compared to the motor cortex. However, the tropism was sufficient to provoke a mnemonic dysfunction.

Based on this, we selected the cerebral hippocampal area for other analyses, aiming to study whether chronic exposure to inorganic $\mathrm{Hg}$ is capable of generating cognitive alterations and/or biochemical modulation, tissue damage, and cell death in the hippocampus of adult rats.

\section{Materials and Methods}

2.1. Ethics Statement. Experiments followed the protocol approved by the Ethics Committee on the use of animals (CEUA, Federal University of Pará, Protocol BIO139-13). They are in accordance with the NIH Guide for the Care and Use of Laboratory Animals and national law for laboratory experimentation [16].

2.2. Animals and Experimental Groups. Male Wistar rats ( $n=56$; 90 days old) from the Federal University of Pará (UFPA) animal facility were kept in collective cages (five animals per cage). The climate and light-controlled room was provided via a $12 \mathrm{~h}$ reverse light/dark cycle (lights on 7:00 a.m.), and animals received food and water ad libitum. Distilled water or $\mathrm{HgCl}_{2}(0.375 \mathrm{mg} / \mathrm{kg} /$ day; $n=20$ per group) was orally administered by gavage over a period of 45 days, according to a procedure previously described by Teixeira et al. [15]. Animals were weighed weekly for $\mathrm{HgCl}_{2}$ dose adjustment.

2.3. Behavioral Assay: Step-Down Inhibitory Avoidance. After $24 \mathrm{~h}$ of $\mathrm{HgCl}_{2}$ or distilled water administration, animals ( $n=14$ per group) were taken to the behavioral test room for $1 \mathrm{~h}$ (acclimation), with controlled noise levels and illumination (12 lux). The step-down inhibitory avoidance apparatus (EP104R, Insight, Brazil) consists of an acrylic box $(50 \times 25 \times 25 \mathrm{~cm})$ with parallel stainless steel bars ( $1 \mathrm{~mm}$ in diameter), a floor connected to an electrical stimulator, and a secure platform $(7 \mathrm{~cm}$ wide $\times 2.5 \mathrm{~cm}$ high $)$ situated against the left wall.

Briefly, the animals were placed in the platform and were free to explore the apparatus for 3 minutes in a habituation session. Twenty-four hours later, the training session was conducted in which each animal was reintroduced to the secure place and the latency of stepping down onto the floor with all four paws was recorded (cut-off $180 \mathrm{~s}$ ). Immediately after the animal step-down response onto the grid floor, a foot shock of $0.4 \mathrm{~mA}$ for $1 \mathrm{~s}$ was performed. In the sequence, the rats were removed from the inhibitory avoidance equipment, and after $1.5 \mathrm{~h}$ and $24 \mathrm{~h}$, they were subjected to the short- and long-term memory test sessions, respectively [17].

2.4. Mercury Levels in the Hippocampus. To validate the exposure to $\mathrm{HgCl}_{2}$ and tissue levels compatible with the dose/time of administration, after the behavioral test, the animals ( $n=7$ per group) were euthanized and each hippocampus sample was weighed ( $0.5 \mathrm{~g}$ maximum of wet weight) in a sample digestion bottle. Then, $1 \mathrm{~mL}$ of distilled water, $2 \mathrm{~mL}$ of nitric acid-perchloric acid with $\mathrm{HNO}_{3}-\mathrm{HClO}_{4}$ (equal proportions), and $5 \mathrm{~mL}$ of sulfuric acid $\left(\mathrm{H}_{2} \mathrm{SO}_{4}\right)$ were sequentially added, followed by heat treatment on a hot plate (200$230^{\circ} \mathrm{C}$ ) for $30 \mathrm{~min}$. Total $\mathrm{Hg}$ content in the samples was estimated by wet digestion, reduction, and cold vapor atomic absorption spectrometry (CVAAS) (semi-automated mercury analyzer, model Hg-201, Sanso Seisakusho Co. Ltd., Tokyo, Japan). The circulation-open airflow system was performed as previously described by Suzuki et al. [18]. The detection limit of the equipment for total $\mathrm{Hg}$ determination was $0.001 \mathrm{mg} \cdot \mathrm{kg}^{-1}$, and the limit of quantification was $0.010 \mathrm{mg} \cdot \mathrm{kg}^{-1}$. The results of the analyses of the samples were expressed in $\mu \mathrm{g} / \mathrm{g}$. The obtained data were tabulated and later submitted to the inferential statistical treatment. The detailed methodology of this analysis is described in a previously published work [15].

2.5. Oxidative Stress. For this analysis, seven animals per group were euthanized by cervical dislocation. The hippocampus was collected and processed for biochemical assays. These animals were not submitted to the inhibitory avoidance equipment. The parameters evaluated were antioxidant capacity against peroxyl radicals (ACAP), evaluated 
through reactive oxygen species (ROS) determination in tissue samples treated or not with a peroxyl radical generator, by fluorimeter [19]; lipid peroxidation (LPO, using malondialdehyde-MDA-as an indicator); and nitrite levels (an indirect marker of nitric oxide production) by spectrophotometry, as previously described [20, 21]. For total protein evaluation, the method proposed by Bradford was used [22]. The results were expressed as percentages of the control groups.

2.6. Assessment and Quantification of Cytotoxicity and Apoptosis. In these assessments, animals ( $n=7$ per group) were euthanized by cervical dislocation and the hippocampus was dissected and treated with collagenase at a concentration of $2 \mathrm{mg} / \mathrm{mL}$ and $4 \mathrm{mg} / \mathrm{mL}$ and stored at $37^{\circ} \mathrm{C}$ for 20 minutes and 40 minutes, respectively, in order to dissociate the tissues (these animals were not submitted to inhibitory avoidance equipment). Thereafter, $100 \mathrm{~mL}$ of solution containing the isolated cells was added to 96-well microplates with $100 \mu \mathrm{L}$ of the CytoTox-Glo ${ }^{\mathrm{TM}}$ Cytotoxicity Assay. This assay uses a luminogenic peptide substrate to measure dead-cell protease activity or Caspase-Glo ${ }^{\circledR}$ 3/7 Assay Systems, a luminescent assay to measure caspase-3/7 activities (Promega, The Netherlands). Readings were performed in a GloMax ${ }^{\circledR}$ (Promega, The Netherlands) according to the manufacturer's recommendations. The quantification results were expressed as percentages of relative fluorescence units (RFU) or relative light units (RLU) relative to the control group, for cytotoxicity and apoptosis, respectively.

\subsection{Histological Evaluation}

2.7.1. Perfusion and Histological Procedures. After behavioral assays, the remaining animals ( $n=7$ per group) were deeply anesthetized with ketamine hydrochloride $(90 \mathrm{mg} / \mathrm{kg}$, i.p.) and xylazine hydrochloride $(10 \mathrm{mg} / \mathrm{kg}$, i.p.), and transcardially perfused with heparinized $0.9 \%$ saline solution followed by $4 \%$ paraformaldehyde in $0.2 \mathrm{M}$ phosphate buffer. Surgical manipulation was performed only after both the corneal and the paw withdraw reflexes were abolished. Brains were removed from the skull and postfixed for $6 \mathrm{~h}$ in Bouin solution. After postfixation, the brain tissue was embedded in paraplast (Monoject Scientific, Athy, Ireland) and sectioned on a microtome at $7 \mu \mathrm{m}$ thick and mounted in silanized slides. The coronal sections containing the anterior hippocampus were located at $-3.60 \mathrm{~mm}$ posterior to Bregma [23].

2.7.2. Immunohistochemistry. Sections of $7 \mu \mathrm{m}$ were submitted to immunohistochemistry analysis. The immunohistochemical procedures were described in our previous investigations $[23,24]$. Briefly, the slides were dewaxed in xylol and hydrated at increasing concentrations of ethanol. Antigenic recovery was performed with citrate buffer at pH 6.0. In order to improve labeling intensity, sections were treated with $0.2 \mathrm{M}$ boric acid ( $\mathrm{pH} 9.0$ ), previously heated to $65^{\circ} \mathrm{C}$ for $25 \mathrm{~min}$. The temperature was maintained constant over the treatment period. Sections were kept at room temperature for $20 \mathrm{~min}$ to decrease the temperature and incubated under constant agitation in a $1 \%$ hydrogen peroxide solution in methanol for $20 \mathrm{~min}$. The sections were rinsed in $0.05 \% \mathrm{PBS} /$ Tween (Sigma Company, USA) solution for 5 min three times and incubated with $10 \%$ normal horse serum (NeuN) and goat serum (GFAP) in PBS for $1 \mathrm{~h}$. Without further rinsing, sections were incubated overnight with the primary antibody in PBS, NeuN (1:500, Miliporere, USA) and GFAP (1:1000, Sigma, USA), rinsed in PBS/ Tween solution for 5 min ( 3 times), and incubated with biotinylated horse anti-mouse (NeuN antibody) and goat antirabbit (GFAP), secondary antibodies (Vector Laboratories, USA) diluted at 1:500 in PBS for $2 \mathrm{~h}$. As a negative control, normal serum, rather than primary antibody, was used in some sections.

Sections were rinsed again for $5 \mathrm{~min}$ (three times) and incubated in the avidin-biotin-peroxidase complex (ABC Kit, Vector Laboratories, USA) for $2 \mathrm{~h}$. Sections were rinsed four times ( $5 \mathrm{~min}$ each) and revealed with diaminobenzidine (DAB). After the DAB reaction, sections were rinsed twice (5 min each) in 0.1 M PB, dehydrated, and cover-slipped with Entellan (Merck, Germany). For more details of this methodology, see $[25,26]$.

2.7.3. Morphometric Analyses. For this quantification, a graticule $\left(1 \mathrm{~mm}^{2}\right)$ attached to the eyepiece (objective $40 \mathrm{x}$, Nikon, Eclipse E200, USA) was used to count three fields per section and three sections per animal in CA1, CA3, and hilus, as described previously [17] and illustrated in Figure 1. NeuN-positive cells corresponding to mature neurons and GFAP-positive cells corresponding to astrocytes were counted. Illustrative images from all experimental groups were obtained with a digital camera (Moticam 2500, USA) attached to a microscope (Nikon, Eclipse 50i, USA).

2.8. Statistical Analysis. All values were tabulated and expressed as mean \pm SEM $(n=14$ animals per group in behavioral test and $n=7$ per group in other analysis) and analyzed for normality using the Shapiro-Wilk test. To analyze body weight, we performed the one-way ANOVA test for repeated measures. Statistical comparisons between groups were performed using the Student's $t$-test. Values of $p \leq 0.05$ were considered statistically significant. GraphPad Prism 5.0 (San Diego, CA, USA) software was used to perform statistical analyses.

The methods are summarized in Figure 1.

\section{Results}

3.1. Chronic $\mathrm{HgCl}_{2}$ Exposure Did Not Alter the Body Weight in Rats. After 45 days of $\mathrm{HgCl}_{2}$ exposure, the body weight of control $(278.1 \pm 2.08 \mathrm{~g})$ and $\mathrm{HgCl}_{2}$-exposed animals $(281.3 \pm 3.00 \mathrm{~g})$ did not differ statistically $(p=0.38)$, as illustrated in Figure 2.

3.2. $\mathrm{HgCl}_{2}$ Exposure in Rats Displays Cognitive Deficits. Chronic exposure by inorganic $\mathrm{Hg}$ during adult life impairs both short- and long-term memory in the inhibitory avoidance task Figure 3 . These results were represented by a reduction in the step-down latency after $1.5 \mathrm{~h}$ training session in the animals exposed to $\mathrm{Hg}(5.60 \pm 1.10 \mathrm{~s})$ when compared to control $(77.60 \pm 22.48 \mathrm{~s} ; p<0.0001)$, as well 


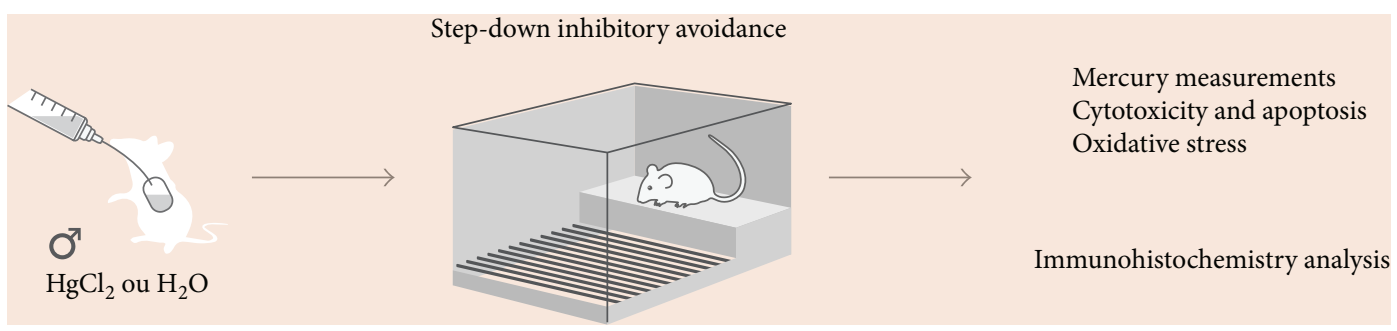

(a)

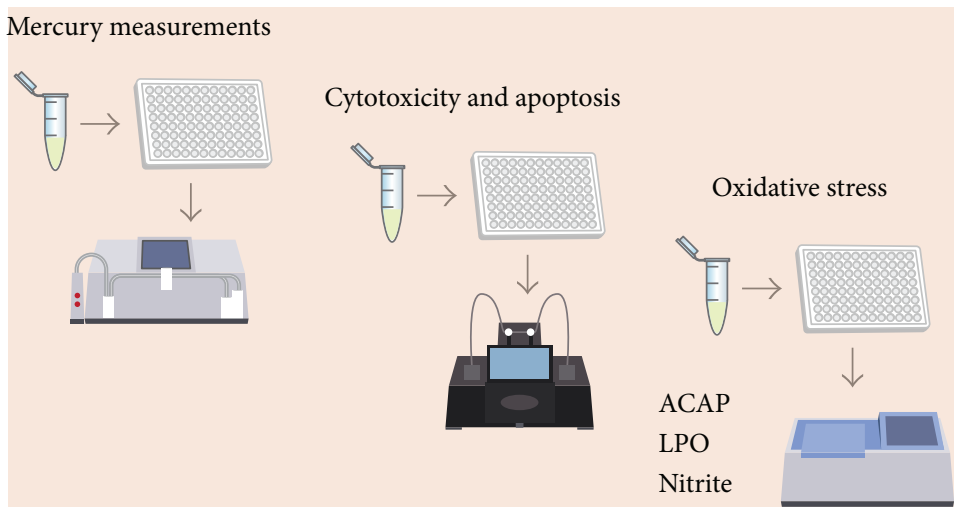

(b)

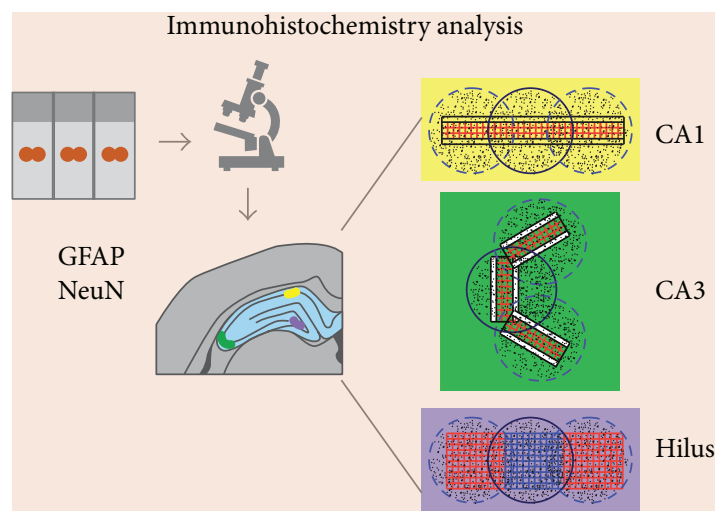

(c)

FIGURE 1: Sample description and experimental stages. Description of the sample and model of exposure to $\mathrm{HgCl}_{2}$; step-down inhibitory avoidance test; division of experimental groups and animal destinations for each stage of analysis (a); total Hg measurement assay, evaluation and quantification of cytotoxicity and apoptosis, and oxidative balance assays (b); immunohistochemistry and morphometric analysis (c).

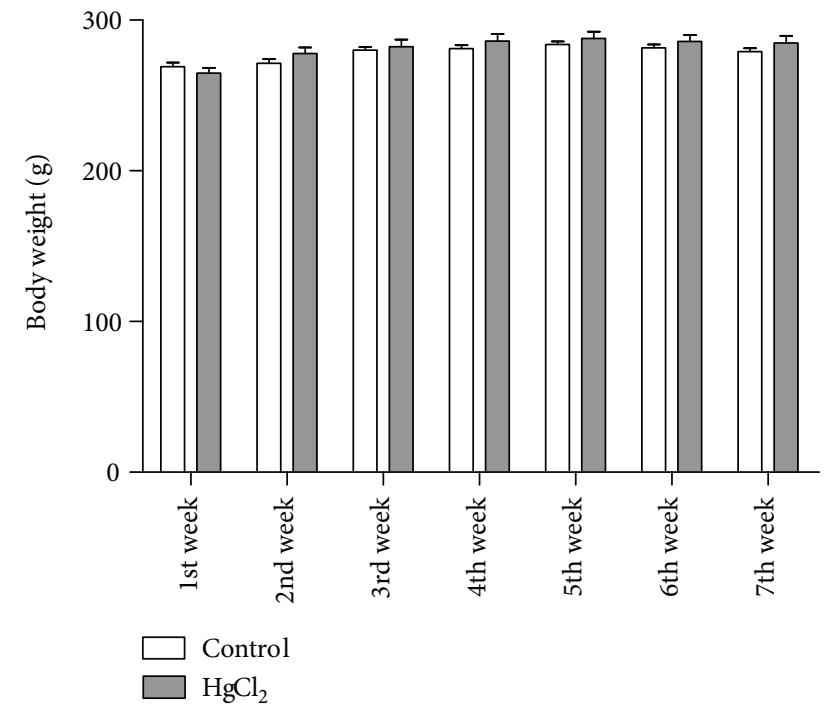

Figure 2: The effects of chronic exposure to $\mathrm{HgCl}_{2}$ on body weight of adult Wistar rats (g). Results are expressed as mean \pm standard error after the two-way ANOVA analysis.

as after the $24 \mathrm{~h}$ training session, in which the exposed animals $(9.30 \pm 1.77 \mathrm{~s})$ presented lower values when compared to control $(93.11 \pm 22.20 \mathrm{~s} ; p<0.0001)$.

3.3. Analysis of Total Hg Levels Revealed the Presence of Metal in the Hippocampus after Chronic Exposure to $\mathrm{HgCl}_{2}$ in Rats. The Hg levels in the hippocampus of control animals $(0.0024 \pm 0.0008 \mu \mathrm{g} / \mathrm{g})$ differ significantly from exposed animals $(0.0404 \pm 0.0026 \mu \mathrm{g} / \mathrm{g} ; p<0.0001)$. Figure 4 displays the $\mathrm{Hg}$ levels in the hippocampus of rats after 45 days of intoxication, in $\mu \mathrm{g} / \mathrm{g}$.

3.4. Chronic $\mathrm{HgCl}_{2}$ Exposure Reduces Antioxidant Capacity against Peroxyl Radicals and Increases Nitrite Levels and Lipid Peroxidation in the Hippocampus of Rats. The $\mathrm{HgCl}_{2}$ exposure decreases the antioxidant capacity against peroxyl radicals in the hippocampus of exposed animals $(41.76 \pm$ $7.68 \%$ ) when compared to control animals (100 $\pm 16.01 \%$; $p=0.0035$; Figure 5(a)). Moreover, the chronic exposure with $\mathrm{HgCl}_{2}$ increased levels of prooxidant parameters, as evidenced by the increased levels of malondialdehyde (lipid peroxidation) in exposed animals $(140.1 \pm 6.08 \%)$, in comparison with the control group $(100 \pm 7.57 \% ; p=0.0028$; Figure 5(b)). The same situation was registered in nitrite levels $\left(\mathrm{HgCl}_{2}=200.9 \pm 9.98 \%\right.$, control $=100 \pm 7.25 \% ; \quad p=$ 0.0003; Figure 5(c)).

3.5. Chronic $\mathrm{HgCl}_{2}$ Exposure Led to Cytotoxicity and Cell Death by Apoptosis. The $\mathrm{HgCl}_{2}$ chronic exposure induced cytotoxicity in the hippocampus of exposed animals (121.9 $\pm 3.39 \%$ RFU) when compared to the control animals (100 $\pm 0.39 \%$ RFU; $p=0.0028$; Figure 6(a)). Besides, the induction of apoptosis was increased in exposed animals $(268.1 \pm 21.00 \%$ RLU) when compared to control (100 \pm 4.29\% RLU; $p<0.0001$; Figure 6(b)).

3.6. Chronic $\mathrm{HgCl}_{2}$ Exposure Reduces the Number of Astrocytes in the Hippocampus. The $\mathrm{GFAP}^{+}$cells in the hippocampus were affected by chronic $\mathrm{HgCl}_{2}$ exposure, as indicated by a 


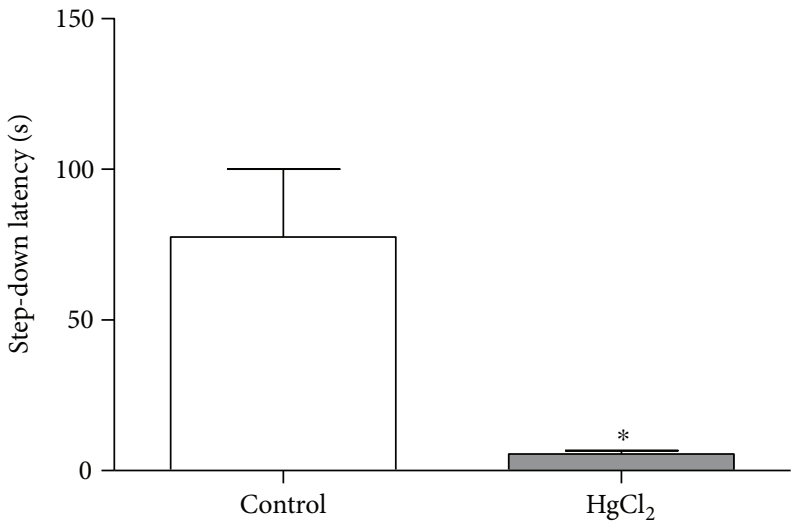

(a)

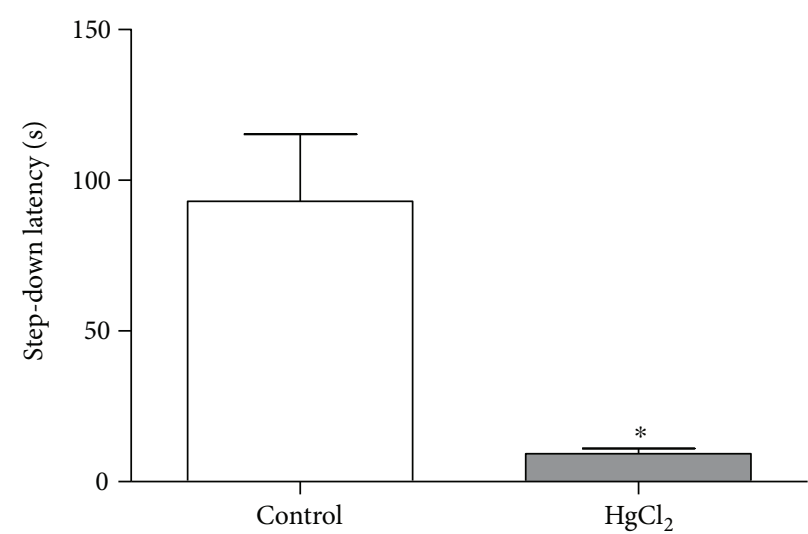

(b)

Figure 3: The effects of $\mathrm{HgCl}_{2}$ exposure $(0.375 \mathrm{mg} / \mathrm{kg} /$ day) for 45 days on the short- and long-term memory of male Wistar rats evaluated in step-down inhibitory avoidance. The results are expressed as the mean \pm SEM of the (a) latency to step down in seconds (1.5 h) and (b) latency to step down in seconds $(24 \mathrm{~h}) .{ }^{*} p<0.05$ compared to the control group (Student's $t$-test).

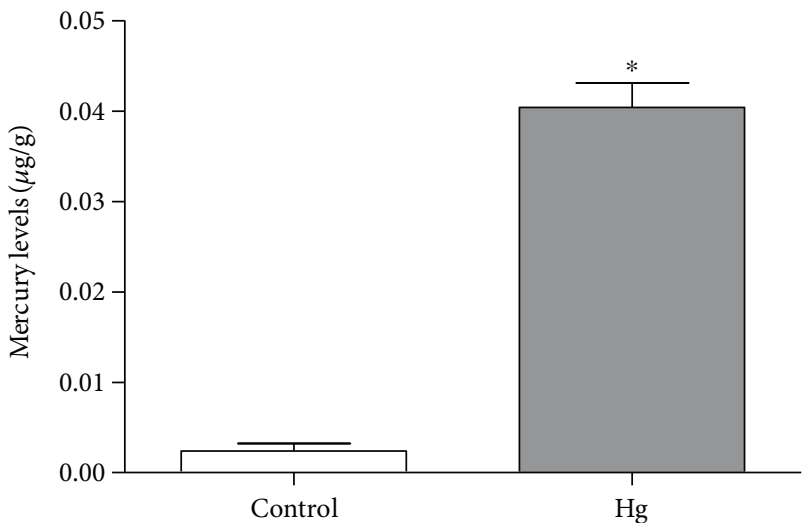

Figure 4: The effects of $\mathrm{HgCl}_{2}$ administration $(0.375 \mathrm{mg} / \mathrm{kg} /$ day $)$ for 45 days on the levels of $\mathrm{Hg}(\mu \mathrm{g} / \mathrm{g})$ in the hippocampus of male Wistar rats. The results are expressed as the mean \pm SEM. ${ }^{*} p<0.05$ compared to the control group (Student's $t$-test).

significant reduction in cell density in all of the regions evaluated: CA1 (control 50.20 \pm 7.29 cells/field; $\mathrm{HgCl}_{2}=25.00 \pm$ 2.64 cells/field; $p=0.043$ ), CA3 (control $74.75 \pm 10.64$ cells/ field; $\mathrm{HgCl}_{2}=31.00 \pm 12.50$ cells/field; $p=0.044$ ), and hilus (control $76.00 \pm 3.50$ cells/field; $\mathrm{HgCl}_{2}=50.00 \pm 4.04$ cells/ field; $p=0.003$ ) (Figure 7).

3.7. Chronic $\mathrm{HgCl}_{2}$ Exposure Induces Neuronal Loss in the Hippocampus. The quantification for $\mathrm{NeuN}^{+}$cells showed that chronic $\mathrm{HgCl}_{2}$ exposure induced a significant neuronal loss in three of the analyzed regions: CA1 (control 163.3 \pm 7.43 cells/field; $\mathrm{HgCl}_{2}=127.8 \pm 5.97$ cells/field; $p=0.0070$ ), CA3 (control $177.5 \pm 4.48$ cells/field; $\mathrm{HgCl}_{2}=99.60 \pm 8.38$ cells/field; $p=0.0001$ ), and hilus (control $167.5 \pm 6.71$ cells/ field; $\mathrm{HgCl}_{2}=123.8 \pm 6.25$ cells/field; $p=0.0021$ ), as illustrated in Figure 8.

\section{Discussion}

This study shows that long-term chronic exposure to $\mathrm{HgCl}_{2}$ in adult rats promotes cognitive impairment, triggering oxidative stress and cell death in the hippocampus. This metal presents a low liposolubility, which disfavors its passage through the blood-brain barrier, especially in adults, with a few investigations described in the literature about the effects in the CNS $[1,2]$. Unfortunately, scarce information is available about inorganic mercury burden in chronically exposed populations because epidemiological studies usually analyzed the total mercury content and not that of the different mercury species [8].

Even in this scenario, we chose to administer $\mathrm{HgCl}_{2}$ by intragastric gavage based on the fact that it represents an important form of intoxication by this metal $[27,28]$, reaching the systemic circulation and possibly crossing the blood-brain barrier and elevating the levels of $\mathrm{Hg}$ in neural parenchyma [15].

Models of chronic exposure to inorganic mercury are relatively uncommon in the literature, although the oral route was already shown to be an important route of chronic exposure to inorganic mercury $[10,11,29]$. Exposure to $0.8 \mathrm{mg} / \mathrm{kg}$ of inorganic mercury in a similar model did not cause obvious symptoms of toxicity in both pregnant rats and their pups (no movement disorder for adults and average body weight of newborns no less than $85 \%$ of controls). In this study, we used less than a half of that dose, characterizing an exposure to a relatively low concentration.

In this study, the analysis of total $\mathrm{Hg}$ levels revealed the presence of $\mathrm{Hg}$ in the hippocampus of chronically exposed rats to $\mathrm{HgCl}_{2}$, demonstrating that, despite its low liposolubility, inorganic $\mathrm{Hg}$ crossed the blood-brain barrier and deposited in the nervous tissue, even at relatively low oral doses. This fact indicates the possibility of exposure to $\mathrm{HgCl}_{2}$ during a prolonged period causing neurotoxic effects.

Hence, the $\mathrm{Hg}$ levels found were able to promote deficits in the short- and long-term memory tasks, evidenced by the inhibitory avoidance paradigm. In this trial, the animals were induced to learn and memorize an event through a noxious stimulus (electric shock). This test contains elements which cause a conflict in the motor response initiated by the animal, which previously held a noxious stimulus (walking on the grid and receiving an electric shock) [30]. 


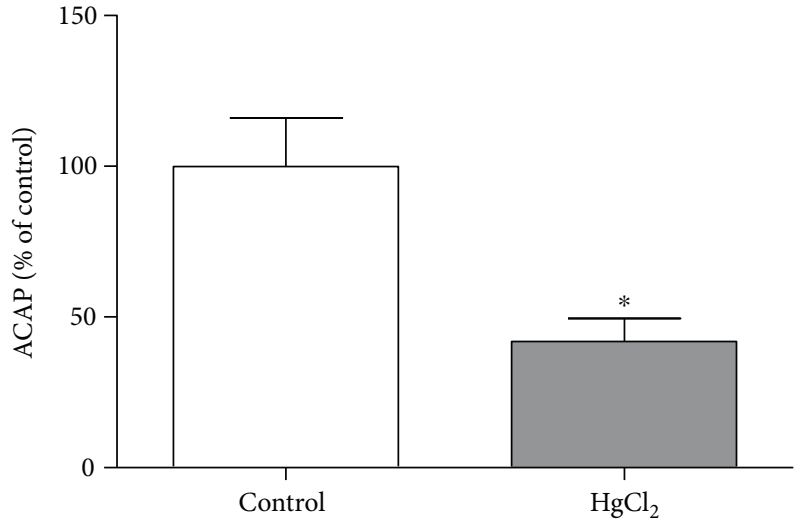

(a)

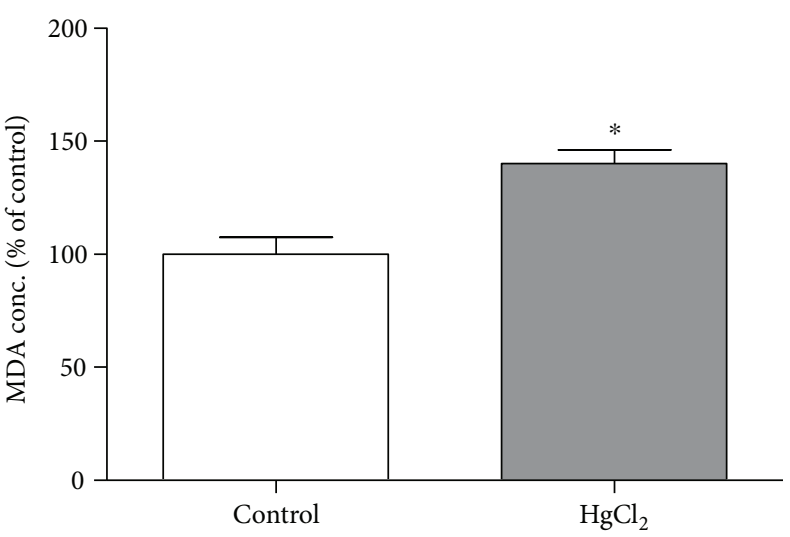

(b)

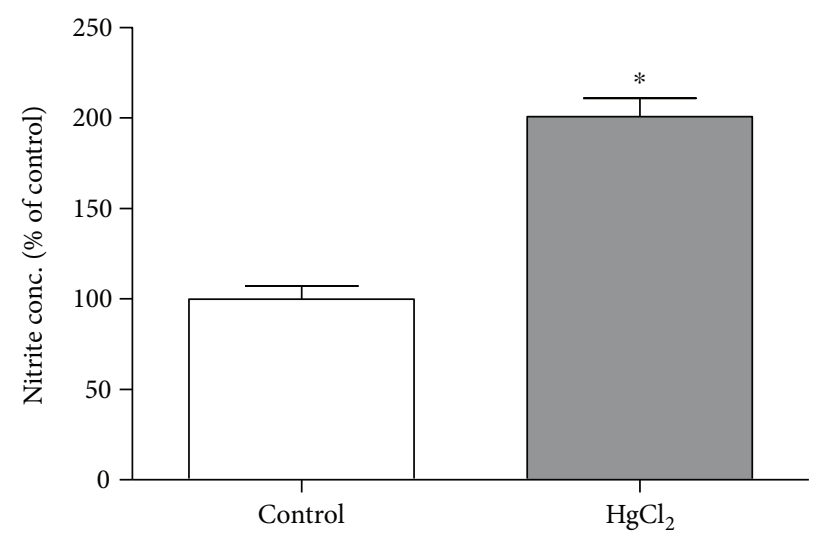

(c)

FIGURE 5: The effects of chronic exposure with $\mathrm{HgCl}_{2}$ on oxidative stress in the hippocampus of adult Wistar rats. The results are expressed as mean \pm standard error of the (a) percentages of the fluorescence unit area difference of the generated curves of the same sample with and without ABAP in comparison to the control group; (b) percentages of milligram per malondialdehyde protein in relation to the control group; and (c) percentages of milligram per nitrite protein in relation to the control group. ${ }^{*} p<0.05$ compared to the control group (Student's $t$-test).

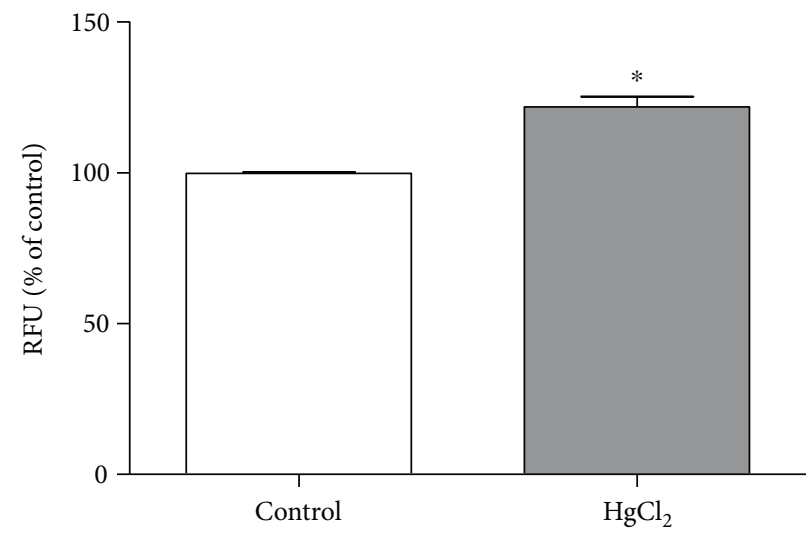

(a)

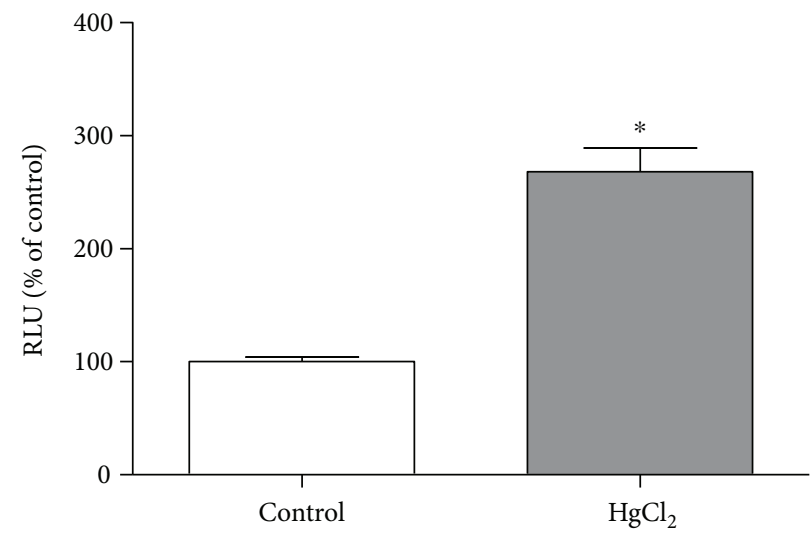

(b)

FIGURE 6: The effects of $\mathrm{HgCl}_{2}$ administration $(0.375 \mathrm{mg} / \mathrm{kg} /$ day $)$ for 45 days on cytotoxicity in the hippocampus of male Wistar rats evaluated in CytoTox-Glo reagent systems and apoptosis evaluated in ApoTox-Glo ${ }^{\circledR}$ reagent systems (Promega). The results are expressed as the mean \pm SEM of the (a) relative fluorescence units (RFU) for cytotoxicity and (b) relative light units (RLU) for apoptosis. ${ }^{*} p<0.05$ compared to the control group (Student's $t$-test).

Mello-Carpes et al. [31] have reported that occupational doses of $\mathrm{HgCl}_{2}$ after 60 days of exposure display deficits on the long-term memory in rats, evaluated $24 \mathrm{~h}$ after the training session. Our study went beyond such results, in which we investigated the short-term memory in the same paradigm. It is important to consider that the inhibitory 


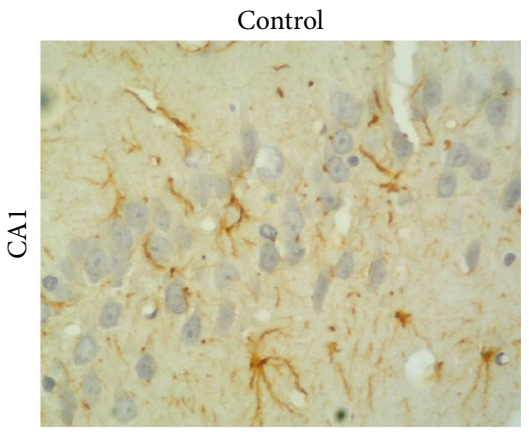

(a)

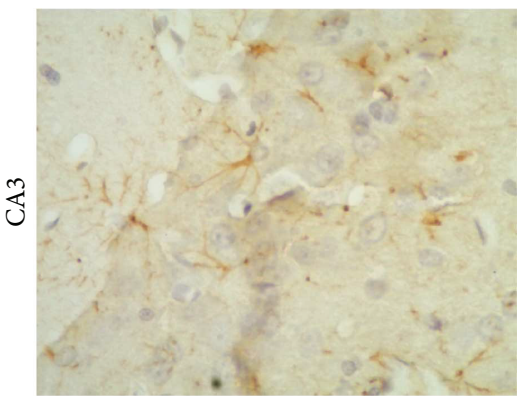

(d)

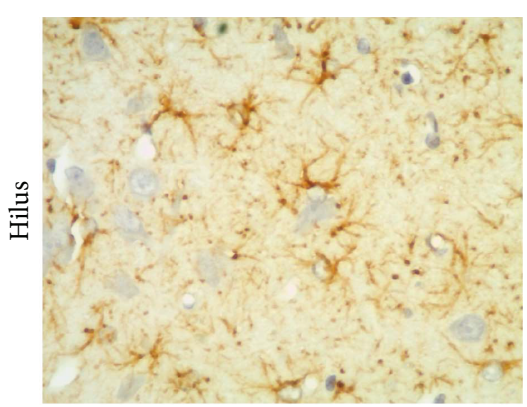

(g)

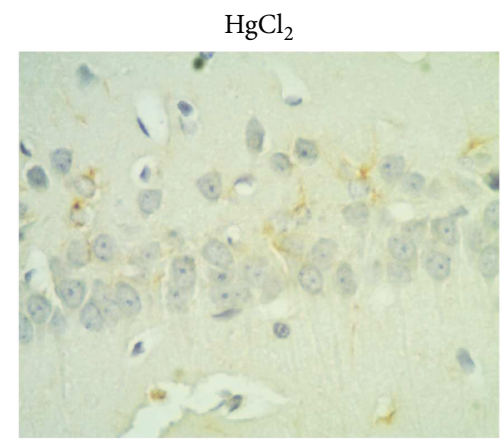

(b)

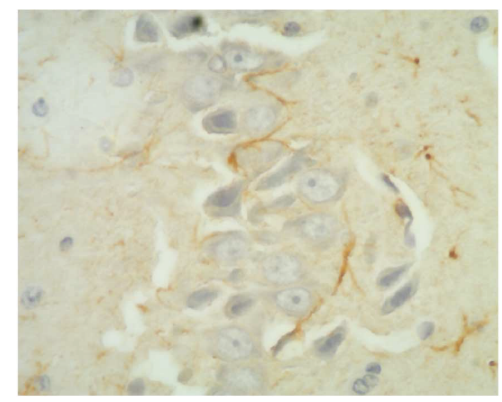

(e)

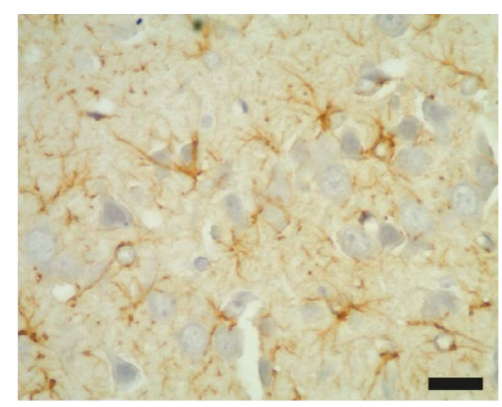

(h)

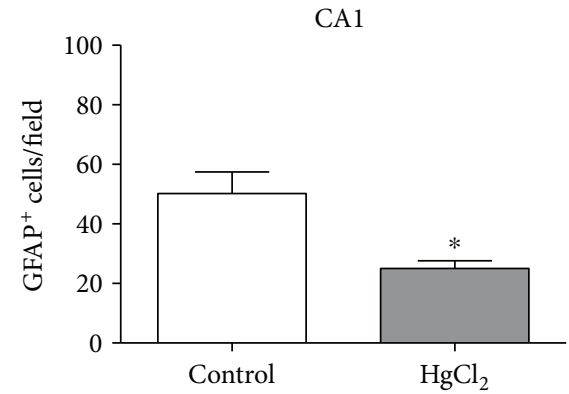

(c)

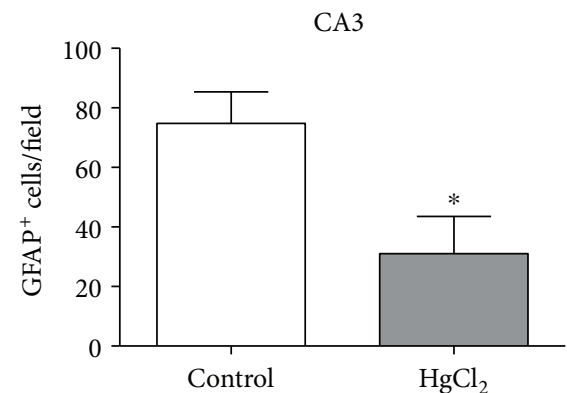

(f)

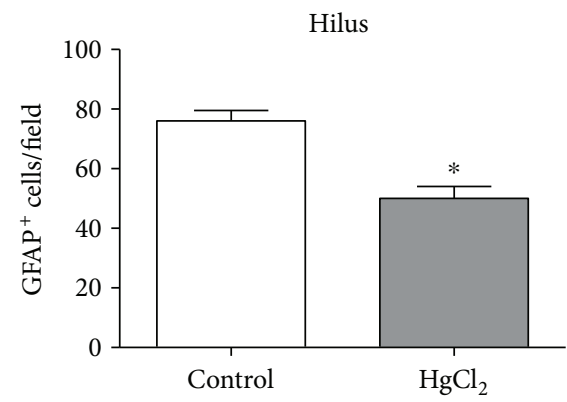

(i)

Figure 7: The effects of chronic exposure to $\mathrm{HgCl}_{2}$ on astrocyte density (GFAP ${ }^{+}$cells) in the CA1 (a-c), CA3 (d-f), and hilus (g-i) of the hippocampus of adult Wistar rats. Results are expressed as mean \pm standard error of the number of cells counted per field in each region $(\mathrm{c}, \mathrm{f}, \mathrm{g}) .{ }^{*} p<0.05$ compared to the control group (Student's $t$-test). Scale bar: $20 \mu \mathrm{m}$.

avoidance test is an essential behavioral assay to evaluate memory function connected to the hippocampus [24, 31, 32].

Inhibitory avoidance memory, a type of fear memory, is formed in the hippocampus, with involvement of the basolateral amygdala [33]. In the hippocampus, especially in the dorsal hippocampus (posterior segment), the regions associated with a fear memory are dorsal CA1 and CA3 [34]. In this investigation, we analyzed the hippocampus as an anamic region of choice for measurements of the levels of $\mathrm{Hg}$, oxidative stress, and cell death.

$\mathrm{Hg}$ presents toxic effects in the CNS, resulting in changes in neurotransmission [34], deficiencies in neuronal differentiation [35], damage to cellular DNA [36, 37], changes in the cytoskeleton [35], variations in intracellular
$\mathrm{Ca}^{2+}$ concentrations [38], and the production of reactive oxygen species (ROS) by configuring the mechanism of oxidative stress [39].

Thus, Hg-induced neurotoxicity is related to the overproduction of reactive oxygen and nitrogen species and/or a reduction of the antioxidant defense system [40-44]. It was demonstrated that chronic exposure to inorganic $\mathrm{Hg}$ promoted increased levels of malondialdehyde (MDA) and nitrites and decreased total antioxidant capacity by promoting oxidative stress in the hippocampus, similar to the results reported by Rizzetti et al., which evidenced the increase in MDA in the brain and plasma [45].

Our results of lipid peroxidation in the hippocampus after inorganic mercury exposure indicated that the 


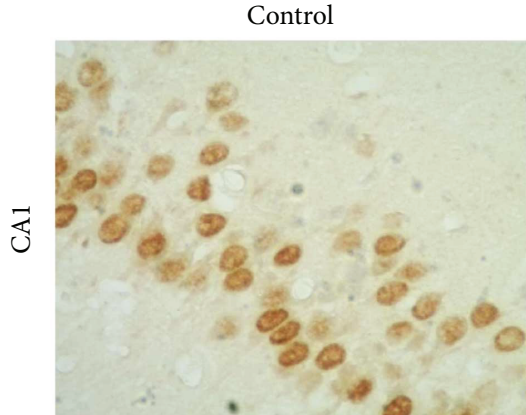

(a)

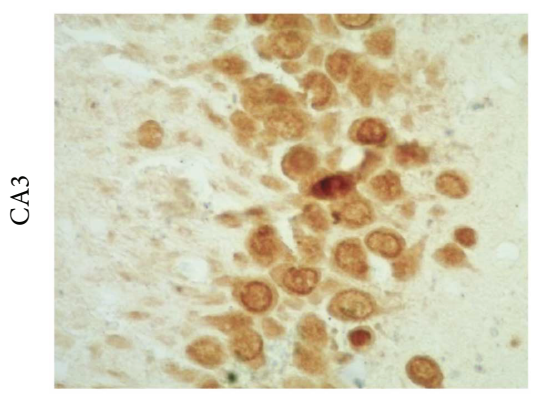

(d)

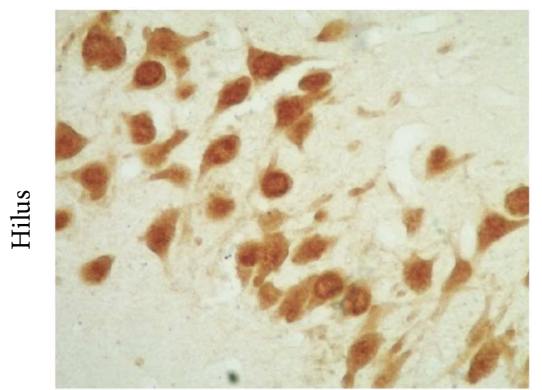

(g)

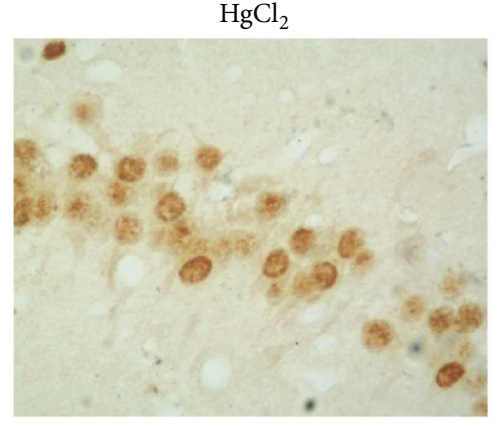

(b)

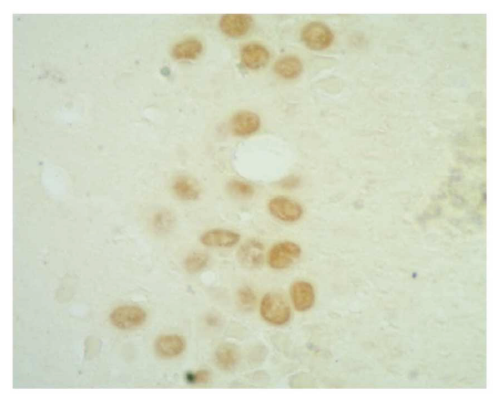

(e)

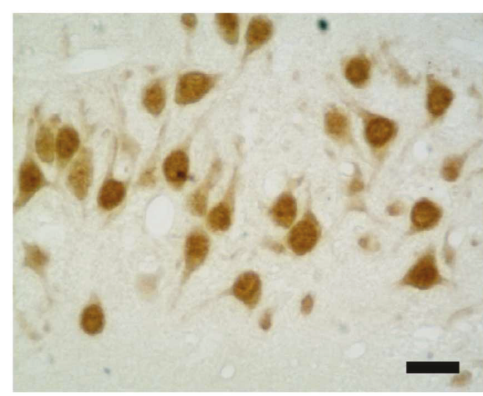

(h)

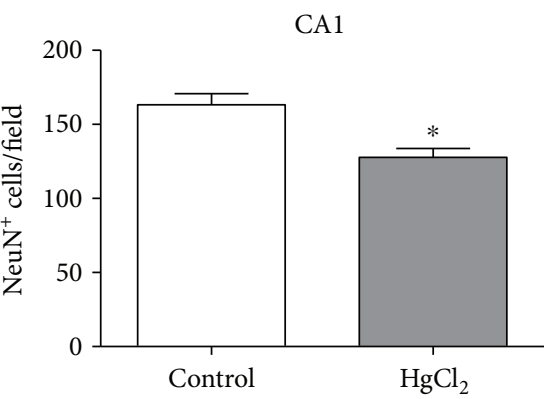

(c)

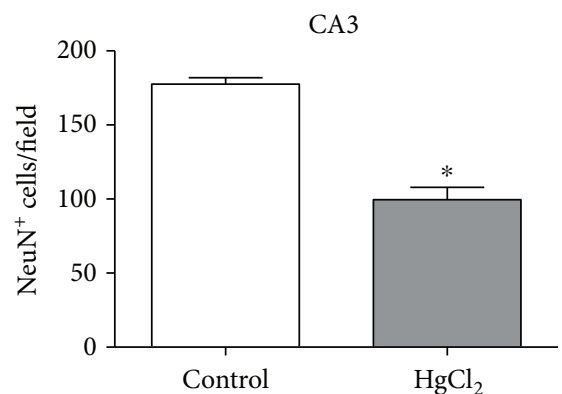

(f)

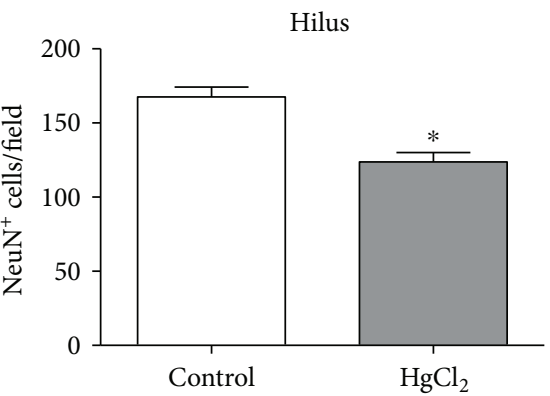

(i)

Figure 8: The effects of chronic exposure to $\mathrm{HgCl}_{2}$ on neuron density (NeuN ${ }^{+}$cells) in the CA1 (a-c), CA3 (d-f), and hilus (g-i) of the hippocampus of adult Wistar rats. Results are expressed as mean \pm standard error of the number of cells counted per field in each region (c, f, g). ${ }^{*} p<0.05$ compared to the control group (Student's $t$-test). Scale bar: $20 \mu \mathrm{m}$.

neurotoxicity induced by $\mathrm{Hg}$ is due to the overproduction of free radicals and products of lipid peroxidation. This is confirmed by the concomitant decrease in total antioxidant capacity, by ACAP analysis. The ability of $\mathrm{Hg}$ to inhibit antioxidant enzymes such as glutathione peroxidase, glutathione reductase, superoxide dismutase, and catalase is already known because of its ability to form free and protein-free complexes, which may decrease or inhibit enzymatic activity $[40,43]$. A recent study by our group revealed that $\mathrm{Hg}$ can modulate the ACAP of salivary glands, as it is a sensitive parameter to mercurial exposure [27].

The levels of $\mathrm{Hg}$ present in the hippocampus, associated with decreased antioxidant capacity and increased prooxidant factors, led us to evaluate the presence of cell death caused by cytotoxicity and the induction of apoptosis in the hippocampus. The chronic exposure to inorganic $\mathrm{Hg}$ in our model promoted cytotoxicity and apoptosis induction.

Similar results have been described based on in vitro studies, in which the inorganic $\mathrm{Hg}$ in cultured astrocytes and neurons promoted cell death by cytotoxicity in both cell types. This process is not associated with apoptotic mechanisms, even after prolonged exposure to the metal [46]. However, in our research, we show that both mechanisms of cell death can be triggered and occur concurrently.

In an animal experimentation model at a dose of $0.4 \mathrm{mg} / \mathrm{kg}$, cell death by apoptosis, triggered by inorganic $\mathrm{Hg}$, may occur from acute exposure, with an increase in caspase- 3 activation and oxidative stress [40]. This occurs 
by an increase in the level of lipid peroxidation and inhibition of nitrite and the enzymatic antioxidant system. This decrease in antioxidant treatment could be represented by the decrease in the activity of superoxide dismutase, catalase, glutathione peroxidase, and glutathione reductase in the CNS [40]. These events are involved in neurotoxicity induced by $\mathrm{Hg}$ in the brain areas, thus increasing cytosolic $\mathrm{Ca}^{2+}$ levels, and therefore acting in a mechanism of cell death, which involves necrosis and the induction of apoptosis $[40,47,48]$. From our results, we can infer that $\mathrm{HgCl}_{2}$ can induce the decrease in both cell density and cytotoxicity by apoptosis, in adult organisms, with the processes occurring simultaneously in the hippocampus.

Chronic exposure to $\mathrm{HgCl}_{2}$ promotes tissue changes in the CA1, CA3, and hilus hippocampal areas, revealed by our immunohistochemical analyses. GFAP is the main protein constituent of the astrocyte cytoskeleton, thus being an important tissue marker [49]. The reduction of immunostaining in $\mathrm{GFAP}^{+}$cell populations due to the neurotoxicity of $\mathrm{HgCl}_{2}$ found in our work points to a disorder of the mnemonic neural processes, since these cells belonging to the glia are auxiliary to the neurons and act in metabolic processes, in synaptic transmission, and in local homeostasis [50]. Previous studies have reported the increased susceptibility of astrocytes to inorganic $\mathrm{Hg}$ toxicity compared to neurons $[51,52]$. This fact agrees with the study of Allen et al. [53], which indicates that the neurotoxicity is due to a deficiency of the astrocytic activity in the maintenance of metabolic pathways and interactions with neurons.

The reduction of neuronal cells in the hippocampal areas analyzed demonstrated the occurrence of the events of cell death caused by chronic exposure to $\mathrm{HgCl}_{2}$. The mechanisms involved in this process may be cytotoxicity or apoptosis, which in turn can be triggered by oxidative stress, as demonstrated in this study. This is in agreement with the results of Lohren et al. [46] which proved the inorganic $\mathrm{Hg}$ cytotoxicity in astrocytes and neurons, even though the occurrence of apoptotic processes was not observed. Another factor associated with this reduction of neuronal cells may be a notable reduction in their replacement due to the reduction of neurogenesis and gliogenesis [54].

Thus, inorganic $\mathrm{Hg}$ reaches and is deposited in the hippocampus. This accumulation promotes the increase of nitric oxide and other ROS levels, affecting membrane lipids and causing lipid peroxidation. The necrosis and apoptosis processes kill cells, both neurons and astrocytes. Finally, the decrease in the number of cells is the main cause of cognitive changes. The results presented in this study indicate the need for social measures and environmental policies aimed at determining the problem of $\mathrm{Hg}$ intoxication in populations living in contaminated regions.

In conclusion, chronic exposure to inorganic $\mathrm{Hg}$ during adulthood promotes cognitive disorders related to decreased cell density in the hippocampus, oxidative stress, cytotoxicity, and apoptosis induction.

\section{Conflicts of Interest}

None of the authors has any conflict of interests.

\section{Authors' Contributions}

Walessa Alana Bragança Aragão and Francisco Bruno Teixeira contributed equally to this work.

\section{References}

[1] K. M. Rice, E. M. Walker Jr., M. Wu, C. Gillette, and E. R. Blough, "Environmental mercury and its toxic effects," Journal of Preventive Medicine and Public Health, vol. 47, no. 2, pp. 74-83, 2014.

[2] R. A. Bernhoft, "Mercury toxicity and treatment: a review of the literature," Journal of Environmental and Public Health, vol. 2012, Article ID 460508, 10 pages, 2012.

[3] P. Holmes, K. A. James, and L. S. Levy, "Is low-level environmental mercury exposure of concern to human health?," Science of The Total Environment, vol. 408, no. 2, pp. 171182, 2009.

[4] S. Kothari, D. Kruse, R. Karimi et al., "High mercury seafood consumption associated with fatigue at specialty medical clinics on Long Island, NY," Preventive Medicine Reports, vol. 2, pp. 798-802, 2015.

[5] R. C. Marques, J. V. Bernardi, M. P. Cunha, and J. G. Dorea, "Impact of organic mercury exposure and home delivery on neurodevelopment of Amazonian children," International Journal of Hygiene and Environmental Health, vol. 219, no. 6, pp. 498-502, 2016.

[6] J. J. Berzas Nevado, R. C. Rodríguez Martín-Doimeadios, M. Jiménez Moreno, J. L. Martins do Nascimento, A. M. Herculano, and M. E. Crespo-López, "Mercury speciation analysis on cell lines of the human central nervous system to explain genotoxic effects," Microchemical Journal, vol. 93, no. 1, pp. 12-16, 2009.

[7] M. E. Crespo-López, A. M. Herculano, T. C. Corvelo, and J. L. Do Nascimento, "Mercury and neurotoxicity," Revue Neurologique, vol. 40, no. 7, pp. 441-447, 2005.

[8] J. J. Berzas Nevado, R. C. Rodríguez Martín-Doimeadios, F. J. Guzmán Bernardo et al., "Mercury in the Tapajós River basin, Brazilian Amazon: a review," Environment International, vol. 36, no. 6, pp. 593-608, 2010.

[9] F. Ruggieri, C. Majorani, F. Domanico, and A. Alimonti, "Mercury in children: current state on exposure through human biomonitoring studies," International Journal of Environmental Research and Public Health, vol. 14, no. 12, p. 519, 2017.

[10] G. P. F. Arrifano, R. C. R. Martín-Doimeadios, M. JiménezMoreno et al., "Large-scale projects in the amazon and human exposure to mercury: the case-study of the Tucuruí dam," Ecotoxicology and Environmental Safety, vol. 147, pp. 299-305, 2018.

[11] R. C. Rodríguez Martín-Doimeadios, J. J. Berzas Nevado, F. J. Guzmán Bernardo et al., "Comparative study of mercury speciation in commercial fishes of the Brazilian Amazon," Environmental Science and Pollution Research International, vol. 1, pp. 1-6, 2014.

[12] L. K. R. Leão, A. M. Herculano, C. Maximino et al., "Mauritia flexuosa L. protects against deficits in memory acquisition and oxidative stress in rat hippocampus induced by methylmercury exposure," Nutritional Neuroscience, vol. 20, no. 5, pp. 297-304, 2017.

[13] A. L. Milioni, B. V. Nagy, A. L. Moura, E. C. Zachi, M. T. Barboni, and D. F. Ventura, "Neurotoxic impact of mercury 
on the central nervous system evaluated by neuropsychological tests and on the autonomic nervous system evaluated by dynamic pupillometry," NeuroToxicology, vol. 59, pp. 263269, 2017.

[14] M. R. Drew and K. A. Huckleberry, "Modulation of aversive memory by adult hippocampal neurogenesis," Neurotherapeutics, vol. 14, no. 3, pp. 646-661, 2017.

[15] F. B. Teixeira, R. M. Fernandes, P. M. Farias-Junior et al., "Evaluation of the effects of chronic intoxication with inorganic mercury on memory and motor control in rats," International Journal of Environmental Research and Public Health, vol. 11, no. 12, pp. 9171-9185, 2014.

[16] Udo Albus, Guide for the Care and Use of Laboratory Animals, National Research Council of the National Academies, Washington, DC, 2011.

[17] A. C. Oliveira, M. C. Pereira, L. N. Santana et al., "Chronic ethanol exposure during adolescence through early adulthood in female rats induces emotional and memory deficits associated with morphological and molecular alterations in hippocampus," Journal of Psychopharmacology, vol. 29, no. 6, pp. 712724, 2015.

[18] T. Suzuki, H. Akagi, K. Akimura et al., Manual of Analyzes of Mercury, Ministry of the Environment, Japan, 2004.

[19] L. L. Amado, M. L. Garcia, P. B. Ramos et al., "A method to measure total antioxidant capacity against peroxyl radicals in aquatic organisms: application to evaluate microcystins toxicity," Science of The Total Environment, vol. 407, no. 6, pp. 2115-2123, 2009.

[20] H. Esterbauer and K. H. Cheeseman, "[42] Determination of aldehydic lipid peroxidation products: malonaldehyde and 4-hydroxynonenal," Methods in Enzymology, vol. 186, pp. 407-421, 1990.

[21] L. C. Green, S. R. Tannenbaum, and P. Goldman, "Nitrate synthesis in the germfree and conventional rat," Science, vol. 212, no. 4490, pp. 56-58, 1981.

[22] M. M. Bradford, "A rapid and sensitive method for the quantitation of microgram quantities of protein utilizing the principle of protein-dye binding," Analytical Biochemistry, vol. 72, no. 1-2, pp. 248-254, 1976.

[23] A. F. Silva, M. S. Aguiar, O. S. Carvalho et al., "Hippocampal neuronal loss, decreased GFAP immunoreactivity and cognitive impairment following experimental intoxication of rats with aluminum citrate," Brain Research, vol. 1491, pp. 2333, 2013

[24] G. B. Oliveira, A. Fontes Ede Jr, S. de Carvalho et al., "Minocycline mitigates motor impairments and cortical neuronal loss induced by focal ischemia in rats chronically exposed to ethanol during adolescence," Brain Research, vol. 1561, pp. 23-34, 2014.

[25] R. R. Lima, J. Guimaraes-Silva, J. L. Oliveira et al., "Diffuse axonal damage, myelin impairment, astrocytosis and inflammatory response following microinjections of NMDA into the rat striatum," Inflammation, vol. 31 , no. 1, pp. 24-35, 2008.

[26] R. R. Lima, L. N. Santana, R. M. Fernandes et al., "Neurodegeneration and glial response after acute striatal stroke: histological basis for neuroprotective studies," Oxidative Medicine and Cellular Longevity, vol. 2016, Article ID 3173564, 15 pages, 2016.

[27] L. O. Bittencourt, B. Puty, S. Charone et al., "Oxidative biochemistry disbalance and changes on proteomic profile in salivary glands of rats induced by chronic exposure to methylmercury," Oxidative Medicine and Cellular Longevity, vol. 2017, Article ID 5653291, 15 pages, 2017.

[28] C. C. Bridges and R. K. Zalups, "Mechanisms involved in the transport of mercuric ions in target tissues," Archives of Toxicology, vol. 91, no. 1, pp. 63-81, 2017.

[29] A. Szász, B. Barna, Z. Gajda, G. Galbács, M. Kirsch-Volders, and M. Szente, "Effects of continuous low-dose exposure to organic and inorganic mercury during development on epileptogenicity in rats," Neurotoxicology, vol. 23, no. 2, pp. 197-206, 2002.

[30] E. Atucha and B. Roozendaal, "The inhibitory avoidance discrimination task to investigate accuracy of memory," Frontiers in Behavioral Neuroscience, vol. 9, p. 60, 2015.

[31] P. B. Mello-Carpes, W. Barros, S. Borges et al., "Chronic exposure to low mercury chloride concentration induces object recognition and aversive memories deficits in rats," International Journal of Developmental Neuroscience, vol. 31, no. 7, pp. 468-472, 2013.

[32] T. Karl, R. Pabst, and S. von Horsten, "Behavioral phenotyping of mice in pharmacological and toxicological research," Experimental and Toxicologic Pathology, vol. 55, no. 1, pp. 69-83, 2003.

[33] I. Izquierdo, C. R. Furini, and J. C. Myskiw, "Fear memory," Physiological Reviews, vol. 96, no. 2, pp. 695-750, 2016.

[34] M. S. Fanselow and H. W. Dong, "Are the dorsal and ventral hippocampus functionally distinct structures?," Neuron, vol. 65, no. 1, pp. 7-19, 2010.

[35] M. C. Chan, E. Bautista, I. Alvarado-Cruz, B. QuintanillaVega, and J. Segovia, "Inorganic mercury prevents the differentiation of SH-SY5Y cells: amyloid precursor protein, microtubule associated proteins and ROS as potential targets," Journal of Trace Elements in Medicine and Biology, vol. 41, pp. 119-128, 2017.

[36] M. E. Crespo-Lopez, A. Costa-Malaquias, E. H. Oliveira et al., "Is low non-lethal concentration of methylmercury really safe? A report on genotoxicity with delayed cell proliferation," PLoS One, vol. 11, no. 9, article e0162822, 2016.

[37] M. E. Crespo-Lopez, A. Lima de Sa, A. M. Herculano, R. Rodriguez Burbano, and J. L. Martins do Nascimento, "Methylmercury genotoxicity: a novel effect in human cell lines of the central nervous system," Environment International, vol. 33, no. 2, pp. 141-146, 2007.

[38] T. L. Limke, J. J. Bearss, and W. D. Atchison, "Acute exposure to methylmercury causes $\mathrm{Ca} 2+$ dysregulation and neuronal death in rat cerebellar granule cells through an M3 muscarinic receptor-linked pathway," Toxicological Sciences, vol. 80, no. 1, pp. 60-68, 2004.

[39] N. Ercal, H. Gurer-Orhan, and N. Aykin-Burns, “Toxic metals and oxidative stress part I: mechanisms involved in metalinduced oxidative damage," Current Topics in Medicinal Chemistry, vol. 1, no. 6, pp. 529-539, 2001.

[40] A. E. Abdel Moneim, "The neuroprotective effect of berberine in mercury-induced neurotoxicity in rats," Metabolic Brain Disease, vol. 30, no. 4, pp. 935-942, 2015.

[41] S. Ceccatelli, E. Dare, and M. Moors, "Methylmercury-induced neurotoxicity and apoptosis," Chemico-Biological Interactions, vol. 188, no. 2, pp. 301-308, 2010.

[42] E. Fonfria, M. T. Vilaro, Z. Babot, E. Rodriguez-Farre, and C. Sunol, "Mercury compounds disrupt neuronal glutamate transport in cultured mouse cerebellar granule cells," Journal of Neuroscience Research, vol. 79, no. 4, pp. 545-553, 2005. 
[43] L. L. Gutierrez, N. G. Mazzotti, A. S. Araujo et al., "Peripheral markers of oxidative stress in chronic mercuric chloride intoxication," Brazilian Journal of Medical and Biological Research, vol. 39, no. 6, pp. 767-772, 2006.

[44] T. Sumathi, C. Shobana, J. Christinal, and C. Anusha, "Protective effect of Bacopa monniera on methyl mercury-induced oxidative stress in cerebellum of rats," Cellular and Molecular Neurobiology, vol. 32, no. 6, pp. 979-987, 2012.

[45] D. A. Rizzetti, F. Fernandez, S. Moreno et al., "Egg white hydrolysate promotes neuroprotection for neuropathic disorders induced by chronic exposure to low concentrations of mercury," Brain Research, vol. 1646, pp. 482-489, 2016.

[46] H. Lohren, L. Blagojevic, R. Fitkau et al., "Toxicity of organic and inorganic mercury species in differentiated human neurons and human astrocytes," Journal of Trace Elements in Medicine and Biology, vol. 32, pp. 200-208, 2015.

[47] S. H. Kim and R. P. Sharma, "Mercury-induced apoptosis and necrosis in murine macrophages: role of calcium-induced reactive oxygen species and p38 mitogen-activated protein kinase signaling," Toxicology and Applied Pharmacology, vol. 196, no. 1, pp. 47-57, 2004.

[48] A. Nakaizumi, T. Horie, T. Kida et al., "Nitric oxide potentiates TNF- $\alpha$-induced neurotoxicity through suppression of NF- $\kappa \mathrm{B}$," Cellular and Molecular Neurobiology, vol. 32, no. 1, pp. 95106, 2012.

[49] O. Sveinsson, L. Herrman, and M. A. Hietala, "Heroininduced acute myelopathy with extreme high levels of CSF glial fibrillar acidic protein indicating a toxic effect on astrocytes," BMJ Case Reports, vol. 2017, 2017.

[50] R. M. Ransohoff and M. A. Brown, "Innate immunity in the central nervous system," The Journal of Clinical Investigation, vol. 122, no. 4, pp. 1164-1171, 2012.

[51] J. S. Charleston, R. L. Body, R. P. Bolender, N. K. Mottet, M. E. Vahter, and T. M. Burbacher, "Changes in the number of astrocytes and microglia in the thalamus of the monkey Macaca fascicularis following long-term subclinical methylmercury exposure," Neurotoxicology, vol. 17, no. 1, pp. 127138, 1996.

[52] R. H. Garman, B. Weiss, and H. L. Evans, "Alkylmercurial encephalopathy in the monkey (Saimiri sciureus and Macaca arctoides): a histopathologic and autoradiographic study," Acta Neuropathologica, vol. 32, no. 1, pp. 61-74, 1975.

[53] J. W. Allen, G. Shanker, K. H. Tan, and M. Aschner, "The consequences of methylmercury exposure on interactive functions between astrocytes and neurons," Neurotoxicology, vol. 23, no. 6, pp. 755-759, 2002.

[54] F. T. Crews, M. A. Collins, C. Dlugos et al., "Alcohol-induced neurodegeneration: when, where and why?," Alcoholism, Clinical and Experimental Research, vol. 28, no. 2, pp. 350364, 2004. 


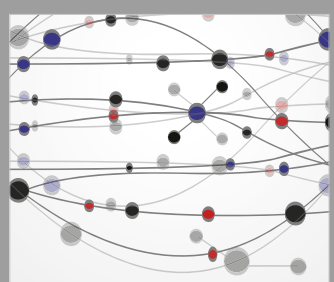

The Scientific World Journal
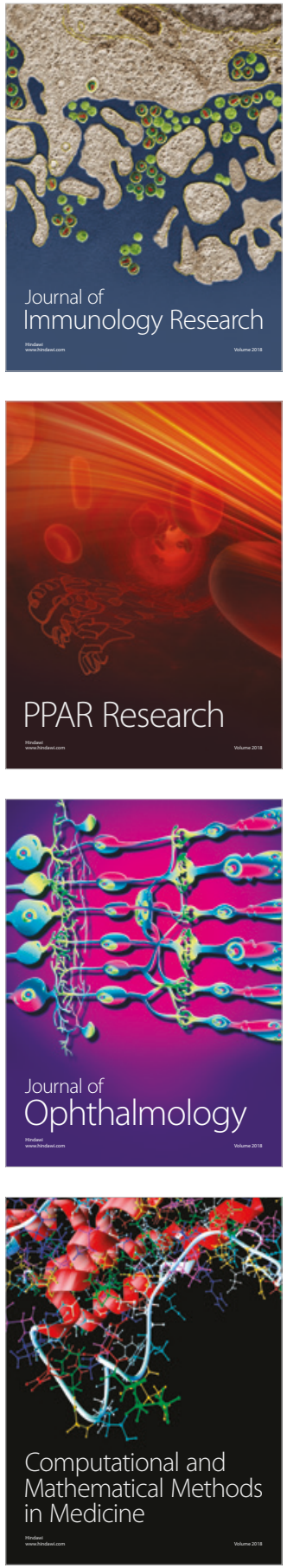

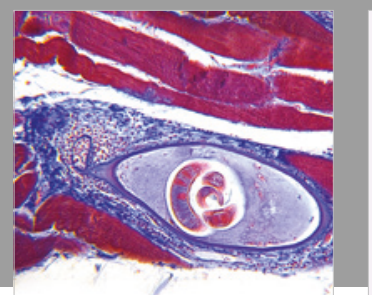

Gastroenterology Research and Practice

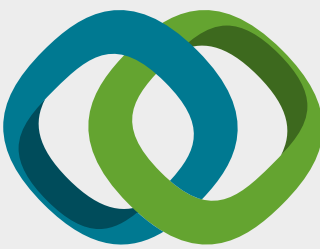

\section{Hindawi}

Submit your manuscripts at

www.hindawi.com
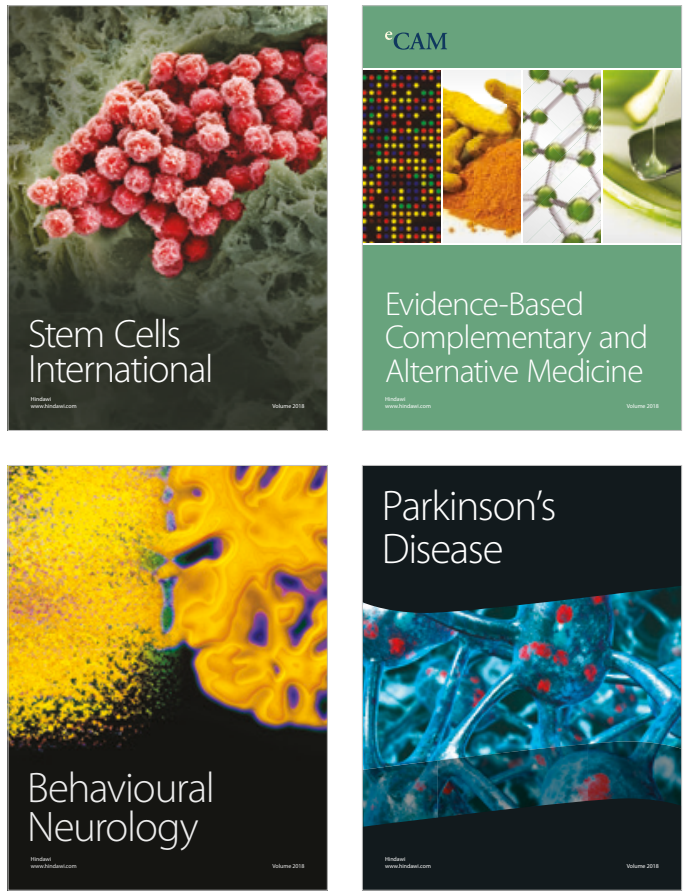

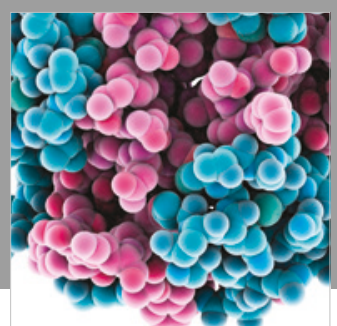

ournal of

Diabetes Research

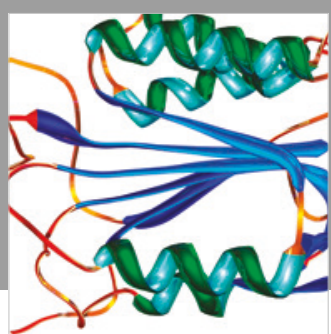

Disease Markers
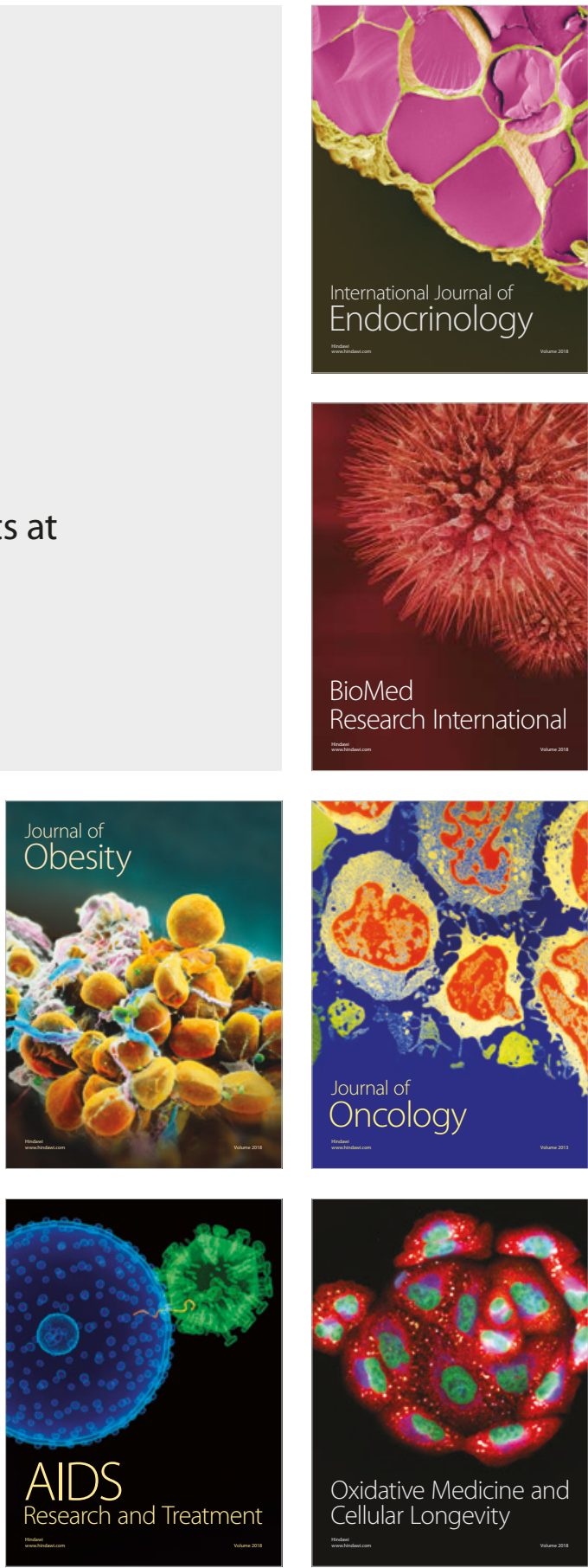